\title{
Effects of Piezoelectric Potential of ZnO on Resistive Switching Characteristics of Flexible $\mathrm{ZnO} / \mathrm{TiO}_{2}$ Heterojunction Cells
}

\author{
HONGXIA LI ® $1,{ }^{1,3}$ YOU ZHOU,${ }^{1}$ GANG DU,${ }^{1}$ YANWEI HUANG, ${ }^{1}$ \\ and $\mathrm{ZHENGUO} \mathrm{JI}^{1,2,4}$ \\ 1.-College of Materials and Environmental Engineering, Hangzhou Dianzi University, \\ Hangzhou 310018, China. 2.-State Key Lab of Silicon Materials, Zhejiang University, \\ Hangzhou 310027, China. 3.—e-mail: hxli@hdu.edu.cn. 4.—e-mail: jizg@hdu.edu.cn
}

Flexible resistance random access memory (ReRAM) devices with a heterojunction structure of $\mathrm{PET} / \mathrm{ITO} / \mathrm{ZnO} / \mathrm{TiO}_{2} / \mathrm{Au}$ were fabricated on polyethylene terephthalate/indium tin oxide (PET/ITO) substrates by different physical and chemical preparation methods. X-ray diffraction, scanning electron microscopy and atomic force microscopy were carried out to investigate the crystal structure, surface topography and cross-sectional structure of the prepared films. X-ray photoelectron spectroscopy was also used to identify the chemical state of $\mathrm{Ti}, \mathrm{O}$ and $\mathrm{Zn}$ elements. Theoretical and experimental analyses were conducted to identify the effect of piezoelectric potential of $\mathrm{ZnO}$ on resistive switching characteristics of flexible $\mathrm{ZnO} / \mathrm{TiO}_{2}$ heterojunction cells. The results showed a pathway to enhance the performance of ReRAM devices by engineering the interface barrier, which is also feasible for other electronics, optoelectronics and photovoltaic devices.

Key words: Piezoelectric potential, interfacial band structure, resistive switching characteristics, heterojunction cell

\section{INTRODUCTION}

Heterojunctions have been used in many fields such as solar cells, photoelectrochemical (PEC) cells, semiconducting lasers, and quantum wells, etc. ${ }^{1-5}$ The interface of the heterojunction is important and greatly influenced by the effect of an energy state discontinuity. The piezoelectric effect is the coupling of piezoelectric polarization $\left(P_{\mathrm{pz}}\right)$ and the intrinsic electric field, which can be used to tune charge transportation of corresponding materials. ${ }^{6-10}$ Previous investigations have verified that the interfacial band structure can be tuned by the piezoelectric effect, ${ }^{9-12}$ which is typically implemented via strain from mechanical deformation. The appropriate compression or tension to the piezoelectric material leads to a piezoelectric potential and thus causes redistribution of the free carrier in the heterostructures. Accordingly, the performance of heterojunctions can

(Received August 29, 2017; accepted December 8, 2017; published online December 19, 2017) be enhanced by engineering the band structure without altering the interface structure or chemistry.

$\mathrm{ZnO}$ exhibits an appreciable piezoelectric effect $^{13-17}$ and can be applied to modulate its semiconductor functionalities. In recent years, piezoelectric polarization of $\mathrm{ZnO}$ has been applied to regulate the band structure of $\mathrm{ZnO}$-related heterojunctions in the fields of light emitting diodes (LEDs), ${ }^{18,19}$ diodes $^{15}$ and memory units. ${ }^{16,17}$

Resistance random access memory (ReRAM) units have been proved to be promising as nextgeneration nonvolatile memory because of their advantages over other nonvolatile memories. ${ }^{20}$ Combining the piezotronic effect with ReRAM devices could tune the energy band structure and thus improve the performance of ReRAM devices. This unique property can be used in reducing the energy consumption in a flexible resistive switching system. In this paper, we firstly study the application of band-structure engineering of $\mathrm{ZnO} / \mathrm{TiO}_{2}$ ReRAM. Piezoelectric $\mathrm{ZnO}$ film was prepared on transparent flexible indium tin oxide (ITO) 
substrates. Switching voltages of the cell were reduced when the $\mathrm{ZnO}$ film was forced to a compressive strain, which was caused by the decrease of barrier height at the $\mathrm{ZnO} / \mathrm{TiO}_{2}$ interface caused by remnant piezoelectric polarization. This study suggests a route to improve the performance of ReRAMs, which also shows promise in enhancing the performance of many other electronic devices.

\section{EXPERIMENTAL DETAILS}

Polyethylene terephthalate/ITO (PET/ITO) substrates were cleaned ultrasonically in acetone, ethanol and ionized water for $20 \mathrm{~min}$. $\mathrm{ZnO}$ film was prepared by radio magnetron sputtering at room temperature by using a $\mathrm{ZnO}$ ceramic target. The flow rate of Ar was $20 \mathrm{sccm}$ and the film thickness was $100 \mathrm{~nm}$ with a 120-min sputtering time. $\mathrm{TiO}_{2}$ film was prepared by atomic layer deposition (ALD) at a substrate temperature of $80^{\circ} \mathrm{C}$. $\mathrm{TiCl}_{4}$ and $\mathrm{H}_{2} \mathrm{O}$ vapors were used as the precursors and injected into the furnace with a $0.5 \mathrm{~s}$ pulse time and separated by $60 \mathrm{~s}$ N2 purging. So, one complete cycle consists of a $0.5 \mathrm{~s} \mathrm{H}_{2} \mathrm{O}$ pulse, $60 \mathrm{~s}$ of $\mathrm{N}_{2}$ purging, a $0.5 \mathrm{~s} \mathrm{TiCl}_{4}$ pulse and $60 \mathrm{~s}$ of $\mathrm{N}_{2}$ purging. The top $\mathrm{Au}$ electrode with a diameter of $100 \mu \mathrm{m}$ was fabricated by E-beam evaporation with a metal shadow mask; so, the flexible ReRAM structure was PET/ITO/ZnO/ $\mathrm{TiO}_{2} / \mathrm{Au}$.

The phase and surface topography of $\mathrm{ZnO}$ thin films were measured by x-ray diffraction (XRD, Bruker D8 Discovery, with $\mathrm{Cu} \mathrm{K} \alpha$ radiation) and scanning electron microscopy (SEM, LEO GEMINI 1530), respectively. The morphology of the $\mathrm{TiO}_{2}$ film was measured by atomic force microscopy (AFM, Park Systems, XE-70) and the cross-sectional image of PET/ITO/ZnO/TiO 2 was analyzed by SEM. X-ray photoelectron spectroscopy (XPS) surface profile measurements were used to verify the chemical state of Ti, $\mathrm{O}$ and $\mathrm{Zn}$ by using a Thermo K-alpha XPS instrument (Thermo Scientific, Waltham, MA, USA). The XPS analysis chamber pressure was about $1 \times 10^{-7} \mathrm{~Pa}$. The energy resolution was $1.17 \mathrm{eV}$ at full width at half maximum (FWHM). $I-V$ characteristics of the $\mathrm{PET} / \mathrm{ITO} / \mathrm{ZnO} / \mathrm{TiO}_{2} / \mathrm{Au}$ device were analyzed by an $I-V$ curve tracer with
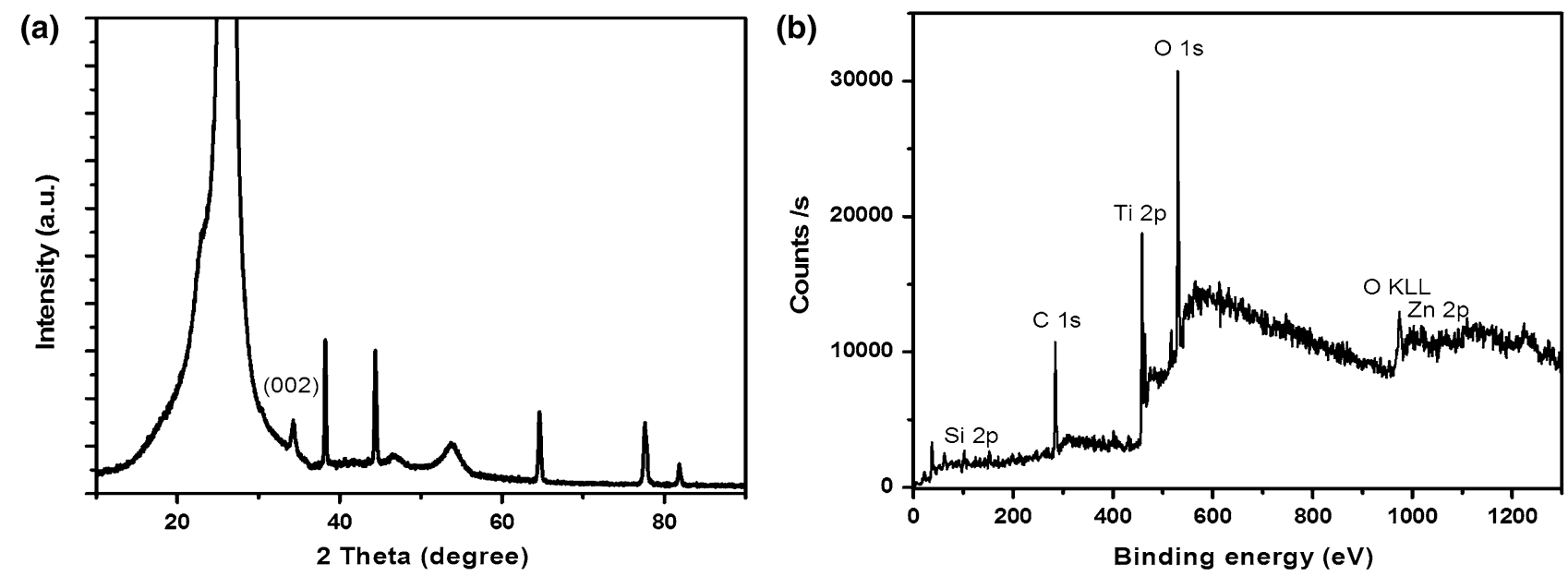

(c)

(d)
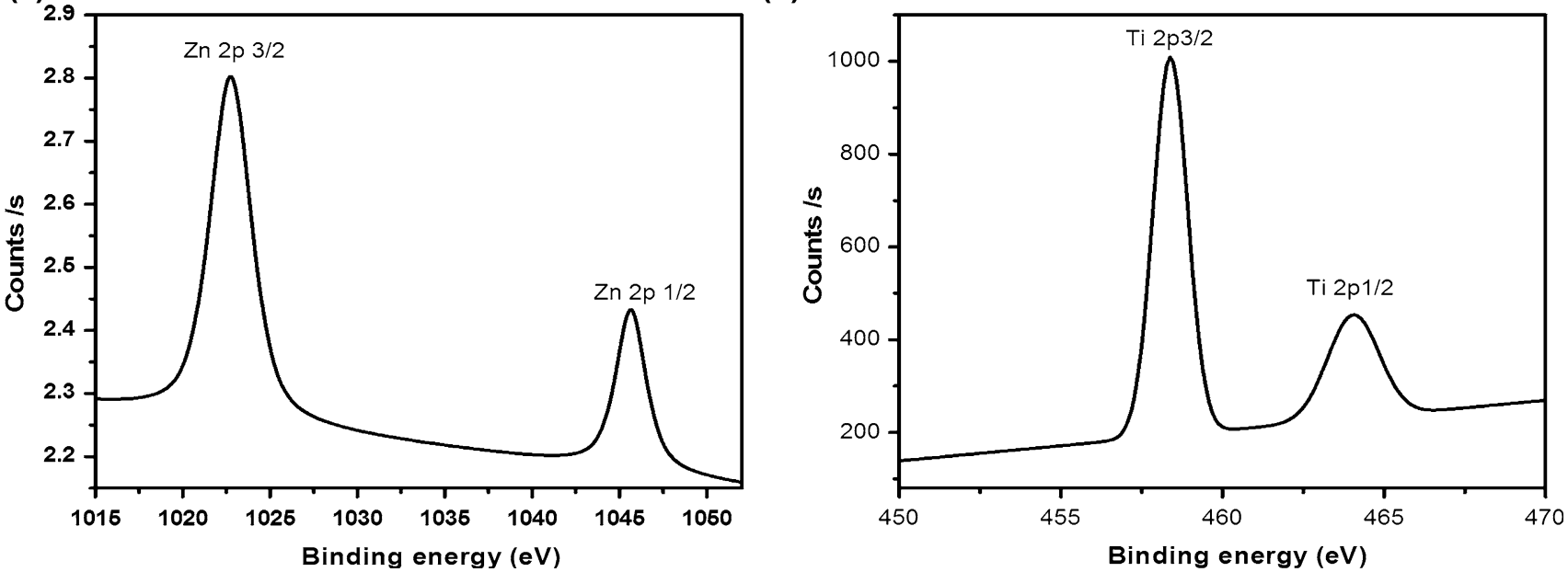

Fig. 1. XRD of PET/ITO/ZnO sample (a), XPS survey spectra of PET/ITO/ZnO/TiO 2 architecture (b), Zn $2 \mathrm{p}$ characteristics of $\mathrm{ZnO}$ films (c) and XPS spectra of Ti $2 p(d)$. 

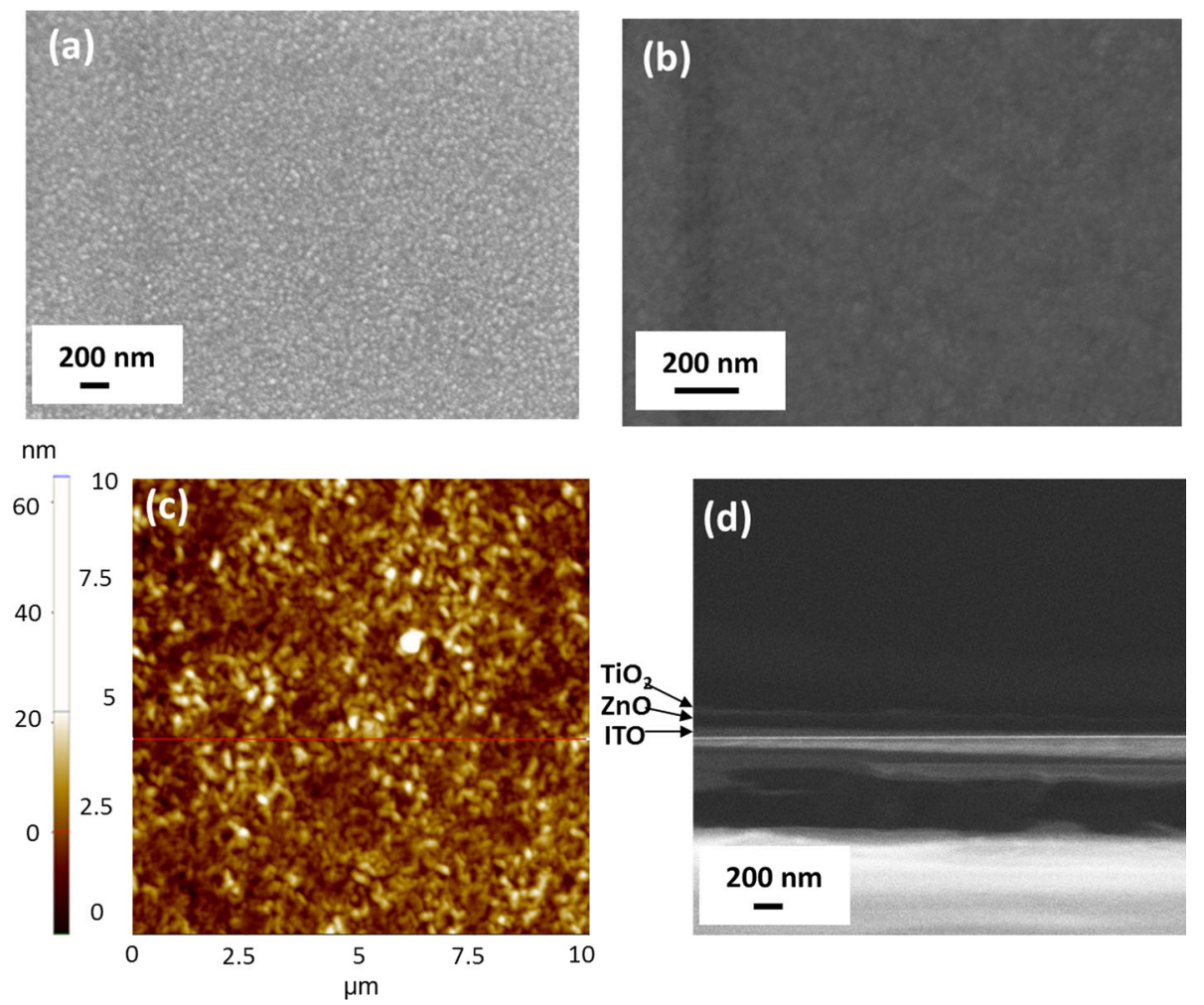

Fig. 2. SEM photograph of $\mathrm{ZnO}$ film (a), SEM image of $A L D \mathrm{TiO}_{2}$ film deposited on $\mathrm{ZnO}$ film (b), AFM photograph of the surface of $\mathrm{TiO}_{2}$ film (c) and cross-sectional image of $\mathrm{PET} / \mathrm{ITO} / \mathrm{ZnO} / \mathrm{TiO}_{2}(\mathrm{~d})$.

scan rate of $0.1 \mathrm{~V} / \mathrm{s}$ and step potential of $0.02 \mathrm{~V}$. During the $I-V$ measurements, a voltage bias was applied to the $\mathrm{Au}$ top electrode while the ITO was grounded. The entire device was attached to a polymethylmethacrylate (PMMA) cantilever $(3 \mathrm{~cm}$ $\times 20 \mathrm{~cm}$ ), which can be deformed to produce $0.2 \%$ compression and tensile strains.

\section{RESULTS AND DISCUSSION}

Figure 1a shows the XRD patterns of $\mathrm{ZnO}$ film fabricated on flexible PET/ITO substrate. Except for the preferential (002) peak of $\mathrm{ZnO}$, all the other peaks come from the substrate. No $\mathrm{TiO}_{2}$ peak was observed for the PET/ITO/ZnO/TiO ${ }_{2}$ sample since it is in an amorphous phase. The full XPS spectrum (Fig. 1b) showed good agreement with all the elements expected in a $\mathrm{ZnO}$ and $\mathrm{TiO}_{2}$ sample. The peak centered at $1022.3 \mathrm{eV}$ is the signature peak of $\mathrm{Zn}^{2+}$ in $\mathrm{ZnO}$, corresponding to the $\mathrm{Zn} \mathrm{2p3/2}$ core level. ${ }^{21-23}$ Its symmetrical shape indicates a perfect stoichiometry of the sputtering $\mathrm{ZnO}$ film (Fig. 1c). By examining the Ti $2 p$ spectra (Fig. 1d), the doublet peaks at $458.4 \mathrm{eV}$ and $464 \mathrm{eV}$ can be ascribed to the $\mathrm{Ti} 2 \mathrm{p} 3 / 2$ and $\mathrm{Ti} 2 \mathrm{p} 1 / 2$ peaks, respectively, which are very close to those observed in the case of bulk $\mathrm{TiO}_{2} \cdot{ }^{24,25}$

The morphology of $\mathrm{ZnO}$ and $\mathrm{TiO}_{2}$ films was characterized using SEM as shown in Fig. 2a and $b$, respectively. The $\mathrm{ZnO}$ films show smooth surfaces with a fine microstructure without cracks and voids.
Amorphous $\mathrm{TiO}_{2}$ film prepared at $80^{\circ} \mathrm{C}$ with 200 cycles of ALD shows the homogeneous morphology, which indicates conformal growth on $\mathrm{ZnO}$ film. The AFM image of $\mathrm{ALD} \mathrm{TiO}_{2}$ film deposited on $\mathrm{ZnO}$ film in Fig. 2c shows a very flat surface with small fluctuations. Figure $2 \mathrm{~d}$ shows the cross-sectional image of the PET/ITO/ZnO/ $\mathrm{TiO}_{2}$ structure. The film thickness of $\mathrm{TiO}_{2}$ was about $30 \mathrm{~nm}$ according to the measurement.

According to electronic structure analysis by first principles computation, ${ }^{26-28}$ energy density of states (EDOS) and projected density of states (PDOS) of the amorphous $\mathrm{TiO}_{2}$ are fairly close to those of crystalline $\mathrm{TiO}_{2}$. So, we use the corresponding semiconductor parameters of crystalline $\mathrm{TiO}_{2}$ during the next illustration of energy band diagrams. According to the work function of $\mathrm{ZnO}$ and $\mathrm{TiO}_{2}$, the energy band diagrams before and after contact are illustrated in the left and right graphs of Fig. 3a, respectively. The switching voltage change caused by piezoelectric effect can be explained using compressive strain as an example. The final band structure of $\mathrm{ZnO} / \mathrm{TiO}_{2}$ is shown in the right graph of Fig. 3b, which reveals the piezoelectric effectinduced band bending on the previous biased band structure. The piezopotential is totally screened under the ideal steady state. Because of the nonideal structure of the $\mathrm{ZnO} / \mathrm{TiO}_{2}$ interface, a remnant polarization at the interface will always be shown. ${ }^{29-31}$ The remaining positive piezoelectric 


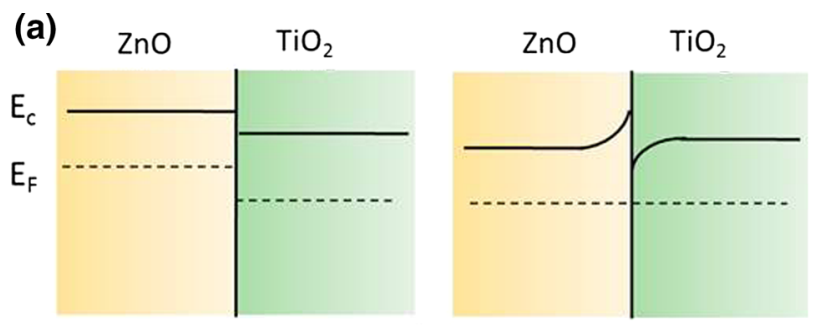

(b)
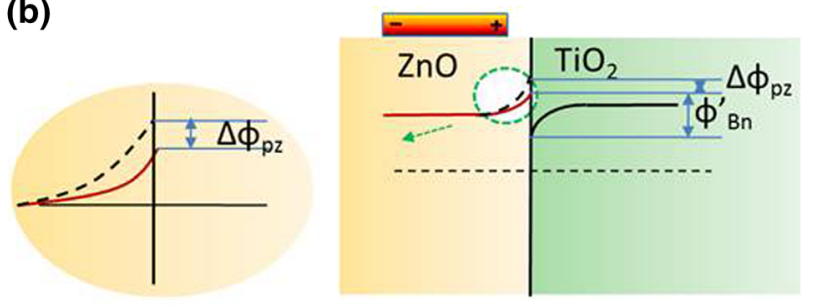

(c)
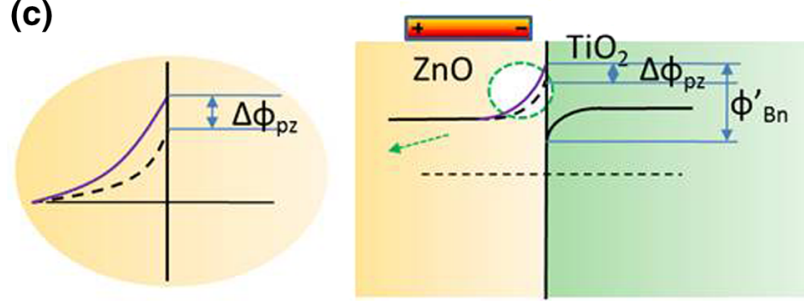

Fig. 3. Schematic band structure diagrams of the $\mathrm{ZnO} / \mathrm{TiO}_{2}$ interface before and after contact $\left(E_{\mathrm{c}}\right.$ : conduction band; $E_{\mathrm{f}}$ : Fermi energy at $T=0 \mathrm{~K}(\mathrm{a})$, schematic illustration of the band lineup of the $\mathrm{ZnO} /$ $\mathrm{TiO}_{2}$ system under compressive (b) and tensile strains (c). The magnified band structure of the $\mathrm{ZnO} / \mathrm{TiO}_{2}$ interface is shown in the ellipse.

charges at the $\mathrm{ZnO} / \mathrm{TiO}_{2}$ interface moves down the $\mathrm{ZnO}$ conduction band locally as shown in the left magnified graph of Fig. $3 \mathrm{~b} . \Delta \phi_{\mathrm{pz}}$ is used to denote the degree of the interfacial band shift. Thus, the barrier height between $\mathrm{ZnO}$ and $\mathrm{TiO}_{2}$ is decreased by $\Delta \phi_{\mathrm{pz}}$ after superimposing the piezopotential. So, the real barrier height is reduced to $\phi_{\mathrm{Bh}}^{\prime}$ $\left(\phi_{\mathrm{Bh}}-\Delta \phi_{\mathrm{pz}}\right)$. Similarly, tilting of the valence band of $\mathrm{ZnO}$ at the $\mathrm{ZnO} / \mathrm{TiO}_{2}$ interface should be inhibited because of the remaining positive piezoelectric charges. Figure $3 \mathrm{c}$ shows the opposite trend under tensile condition. The barrier height between $\mathrm{ZnO}$ and $\mathrm{TiO}_{2}$ is increased by $\Delta \phi_{\mathrm{pz}}$ with a final value to $\phi_{\mathrm{Bh}}^{\prime}\left(\phi_{\mathrm{Bh}}+\Delta \phi_{\mathrm{pz}}\right)$ for tensile strain application. There also exists band bending at the ITO/ZnO interface induced by $P_{\mathrm{pz}}$. However, the effect of charge redistribution at the ITO/ZnO interface is insignificant due to the very short screening length of ITO $(\approx 0.1 \mathrm{~nm})^{30,31}$ and the small discrepancy of work function values between ITO and $\mathrm{ZnO}{ }^{32}$ So, in this paper, we just discuss the piezoelectric-induced band bending at the interface between $\mathrm{ZnO}$ and $\mathrm{TiO}_{2}$.
Figure 4a shows $I-V$ characteristics of PET/ITO/ $\mathrm{ZnO} / \mathrm{TiO}_{2} / \mathrm{Au}$ cells with a direct-voltage sweeping mode. We can see that all the cells had unipolar switching behaviors. The device was initially in a low-resistance state (LRS) and switched to a highresistance state (HRS) with a reset voltage of $3.30 \mathrm{~V}$. Then, while applying the voltage from zero to about $2.26 \mathrm{~V}$, the cell was changed back to a LRS via the set process. The nonvolatile switching was achieved with this method. Here, the device shows the so-called peculiar unipolar switching characteristics, as other papers have reported, ${ }^{20,33}$ since the reset voltage is higher than the set voltage. However, it should be mentioned that PET/ITO/ZnO/ $\mathrm{TiO}_{2} / \mathrm{Au}$ devices are initially in the LRS, which is different from the initial HRS of the referenced paper. ${ }^{33}$ So, it implies that there may exist other possible switching mechanisms other than the charge trapping/de-trapping model which need further study in this field. In order to experimentally demonstrate the influence of piezoelectric polarization on the resistive switching performance of PET/ ITO $/ \mathrm{ZnO} / \mathrm{TiO}_{2} / \mathrm{Au}$ cells, the switching voltage variations of $\mathrm{PET} / \mathrm{ITO} / \mathrm{ZnO} / \mathrm{TiO}_{2} / \mathrm{Au}$ cells for 30 cycles without strain application were measured at room temperature as a comparison. Figure $4 \mathrm{~b}$ shows that the average set voltage was about $2.17 \mathrm{~V}$, while the average reset voltage was about $3.69 \mathrm{~V}$ without strain to the device. When $0.2 \%$ compressive strain was imposed on the $\mathrm{PET} / \mathrm{ITO} / \mathrm{ZnO} / \mathrm{TiO}_{2} / \mathrm{Au}$ flexible cell, the average values of set and reset voltage in Fig. 4c were decreased to about $2.04 \mathrm{~V}$ and $3.55 \mathrm{~V}$, respectively, which is about a $5.99 \%$ and $3.79 \%$ decrease compared with the values without strain application. This is caused by the reduction of barrier height between $\mathrm{ZnO}$ and $\mathrm{TiO}_{2}$ as mentioned before. However, the average values of set and reset voltage were increased to about $2.29 \mathrm{~V}$ and $3.97 \mathrm{~V}$, respectively, as shown in Fig. 4 d, under $0.2 \%$ tensile strain, which is consistent with the theoretical simulation. So, the above experimental results confirm the possibility of modulating the performance of ReRAM by applying piezoelectric polarization.

\section{CONCLUSIONS}

In conclusion, we provide a route to reduce the switching voltages of ReRAMs by modulating the interface band structure of a $\mathrm{ZnO} / \mathrm{TiO}_{2}$ device by piezoelectric potential. The reset and set voltages increased/decreased when the PET/ITO/ZnO/TiO $2 /$ $\mathrm{Au}$ flexible cell was measured with tensile/compressive strain, respectively. The remnant polarization is related to both materials and interfacial properties. Our system showed an $\sim 5.99 \%$ and $3.79 \%$ switching voltage decrease under $0.2 \%$ compressive strain and could be improved for devices that hold higher remnant piezopotential. The piezotronic engineering strategy gives ways to improve the 
(a)

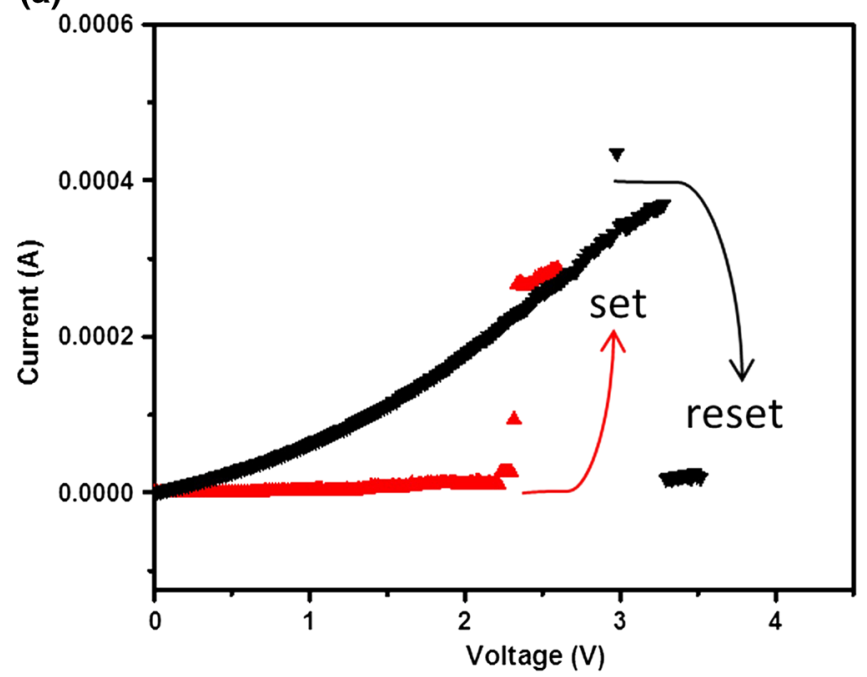

(c)

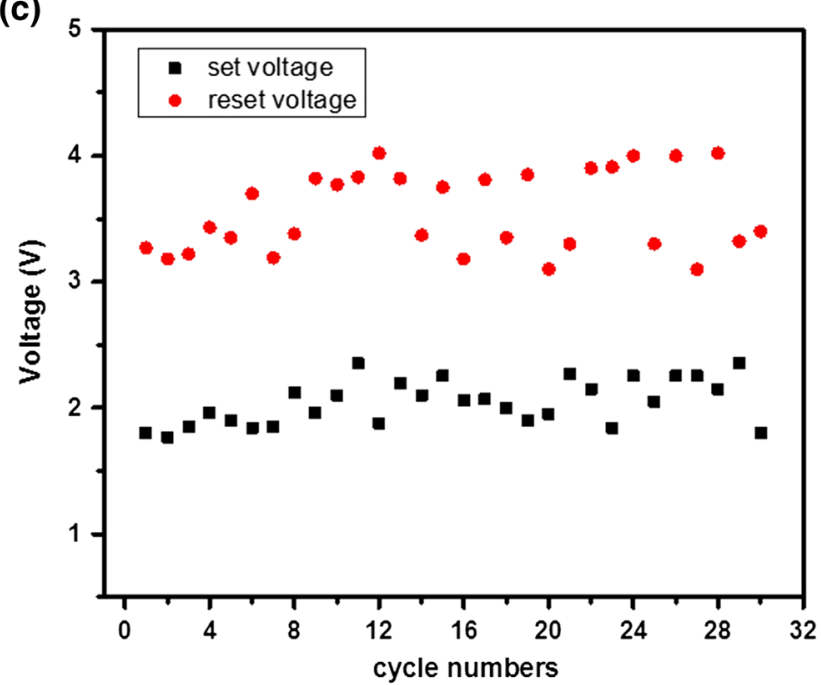

(b)

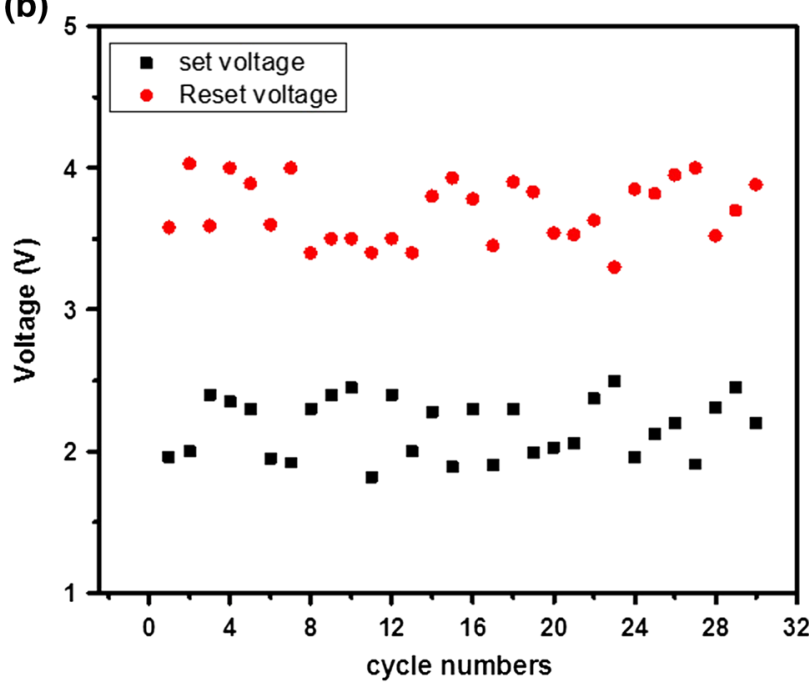

(d)

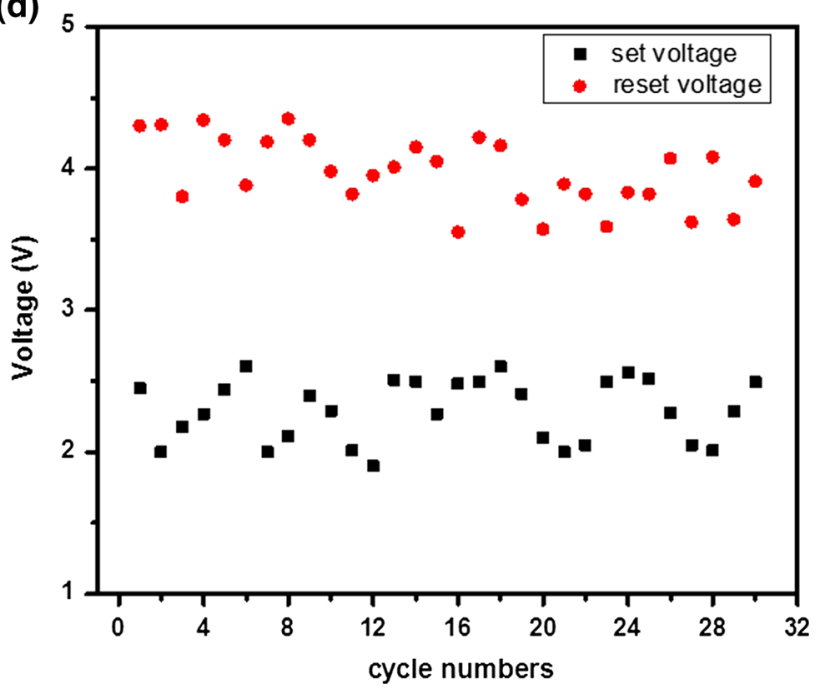

Fig. 4. Linear plot of $I-V$ characteristics of a $\mathrm{PET} / \mathrm{ITO} / \mathrm{ZnO} / \mathrm{TiO}_{2} / \mathrm{Au}$ structure (a), variations of set and reset voltage as a function of cycle numbers of $\mathrm{PET} / \mathrm{ITO} / \mathrm{ZnO} / \mathrm{TiO}_{2} / \mathrm{Au}$ cell without strain (b), with compressive (c) and tensile strain (d), respectively.

efficiency of many electronics, optoelectronics and photovoltaic devices by introducing $\mathrm{P}$ pz.

\section{ACKNOWLEDGEMENTS}

The financial aids of Zhejiang Provincial Natural Science Foundation of China (Grant No. LGG18E020004) and Chinese National Natural Science Foundation (Grant Nos. 61704042 and 61504034) are gratefully acknowledged.

\section{REFERENCES}

1. Q. Yang, X. Guo, W. Wang, Y. Zhang, S. Xu, D.H. Lien, and Z.L. Wang, ACS Nano 4, 6285 (2010).

2. Y. Yu, Z. Zhang, X. Yin, A. Kvit, Q. Liao, Z. Kang, X. Yan, Y. Zhang, and X.D. Wang, Nat. Energy 2, 17045 (2017).

3. Y. Yu, J. Li, D. Geng, J. Wang, L. Zhang, T.L. Andrew, M.S. Arnold, and X.D. Wang, ACS Nano 9, 564 (2015).

4. H. Li, Y. Yu, M.B. Starr, Z. Li, and X.D. Wang, J. Phys. Chem. Lett. 6, 3410 (2015).

5. F. Fan, S. Turkdogan, Z. Liu, D. Shelhammer, and C.Z. Ning, Nat. Nanotechnol. 10, 796 (2015).
6. Z.L. Wang, Adv. Mater. 19, 889 (2007).

7. Z.L. Wang, J. Phys. Chem. Lett 1, 1388 (2010).

8. Y. Zhang, Y. Liu, and Z.L. Wang, Adv. Mater. 23, 3004 (2011).

9. V.M. Voora, T. Hofmann, M. Brandt, M. Lorenz, M. Grundmann, N. Ashkenov, H. Schmidt, N. Ianno, and M. Schubert, Phys. Rev. B 81, 2498 (2010).

10. L. Pintilie and M. Alexe, J. Appl. Phys. 98, 124103 (2005).

11. P. Zubko, D.J. Jung, and J.F. Scott, J. Appl. Phys. 100, $114112(2006)$

12. Y. Watanabe, Phys. Rev. B 57, 789 (1998).

13. A. Bykhovski, B. Gelmont, M. Shur, and A. Khan, J. Appl. Phys. 77, 1616 (1995).

14. S.-H. Park and S.-L. Chuang, Appl. Phys. Lett. 72, 3103 (1998).

15. J. Zhou, P. Fei, Y. Gu, W. Mai, Y. Gao, R. Yang, G. Bao, and Z.L. Wang, Nano Lett. 8, 3973 (2008).

16. W. Wu and Z.L. Wang, Nano Lett. 11, 2779 (2011).

17. J. Song, Y. Zhang, C. Xu, W. Wu, and Z.L. Wang, Nano Lett. 11, 2829 (2011).

18. Q. Yang, W. Wang, S. Xu, and Z.L. Wang, Nano Lett. 11, 4012 (2011).

19. Y. Hu, Y. Zhang, Y. Chang, R.L. Snyder, and Z.L. Wang, ACS Nano 4, 4220 (2010). 
20. F. Pan, S. Gao, C. Chen, C. Song, and F. Zeng, Mater. Sci. Eng., $R$ 83, 1 (2014).

21. Z. Li, F. Wang, A. Kvit, and X. Wang, J. Phys. Chem. C 119, 4397 (2015).

22. F. Wang, J.E. Jakes, D. Geng, and X. Wang, ACS Nano 7, 6007 (2013).

23. F. Wang, J.H. Seo, Z. Ma, and X. Wang, ACS Nano 6, 2602 (2012).

24. K.A. Bogle, M.N. Bachhav, M.S. Deo, N. Valanoor, and S.B. Ogale, Appl. Phys. Lett. 95, 203502 (2009).

25. J.W. Quilty, A. Shibata, J.Y. Son, K. Takubo, T. Mizokawa, H. Toyosaki, T. Fukumura, and M. Kawasaki, Phys. Rev. Lett. 96, 027202 (2006).

26. K.K. Ghuman and C.V. Singh, J. Phys. Condens. Mater. 25, 475501 (2013)
27. G. Marcì, V. Augugliaro, M.J. López-Muñoz, C. Martín, L. Palmisano, V. Rives, M. Schiavello, R.J.D. Tilley, and A.M. Venezia, J. Phys. Chem. B 105, 1026 (2001).

28. B. Prasai, B. Cai, M.K. Underwood, J.P. Lewis, and D.A. Drabold, J. Mater. Sci. 47, 7515 (2012).

29. J. Shi, M.B. Starr, and X. Wang, Adv. Mater. 24, 4683 (2012).

30. J. Shi, M.B. Starr, H. Xiang, Y. Hara, M.A. Anderson, J.H. Seo, Z. Ma, and X. Wang, Nano Lett. 11, 5587 (2011).

31. J. Shi, P. Zhao, and X. Wang, Adv. Mater. 25, 916 (2013).

32. J.F. Wager, Thin Solid Films 516, 1755 (2008).

33. L.D. Bozano, B.W. Kean, V.R. Deline, J.R. Salem, and J.C. Scott, Appl. Phys. Lett. 84, 607 (2004). 